\title{
Um arquivo aberto de Ana Luísa Janeira: a transformação pela viagem
}

\author{
An open archive by Ana Luísa Janeira: changing through travel
}

(iD) Judite Zamith Crus

Doutorada em psicologia

Instituto de Educação, da Universidade do Minho — Uminho.

Braga - Portugal.

juditezc@ie.uminho.pt

Resumo: O objeto do artigo é a análise textual de dois posts do blogue ArquivoVivido, de JANEIRA (17 dez. 2020): para uma epistemologia de viagem; e Viajar, colecionar, arquivar — Coisas \& loisas de muitas paragens com saberes, sabores e odores. A questão de pesquisa centra-se em apreciar a influência educativa precoce da leitura, a criação de mundos virtuais, para a construção do espírito de descoberta, nomeadamente por auscultar-se a história nas facetas de romance verdadeiro e ficção verbal ou virtual. O modelo teórico e metodológico foi a análise crítica de discurso (ÍÑIGUEZ-RUEDA, 2006), orientado a relações entre conceitos: verdade histórica, personalidade de Fernão Mendes Pinto, epistemologia de viagem, imaginação do espaço em mundos possíveis, transição de séculos XVI-XVIII, património material, legado espiritual, botica medieval, cura e saber-fazer. Destaca-se a comparação entre mundos reais e virtuais, num apelo a possibilidades duma hermenêutica dupla, segundo um foco de "imaginação racional".

Palavras chave: análise textual; peregrinação; significados; arqueologia-genealogia foucaultiana; realidades.

Abstract: The object of this article is the textual analysis of two blog posts from the blog ArquivoVivido, by JANEIRA (17 Dec. 2020): para uma epistemologia de viagem; e Viajar, colecionar, arquivar — Coisas \& loisas from several places with knowledge, flavours and odours. The focus of this research was on evaluating the importance of the early educational influence of reading, the creation of virtual worlds, the construction of the discovery spirit, such as listening to true romance and verbal or virtual fictional histories. It was used a critical discourse analysis model for the following relations between concepts: historical truth, personality of Fernão Mendes Pinto, travel epistemology, space imagination in possible worlds, the transition from 16th to 18th century, material heritage, spiritual legacy, medieval pharmacy, healing and know-how. This work concludes with the comparison between real and virtual worlds, an appeal to a double hermeneutics with the focus of "rational imagination".

Key-words: textual analysis; pilgrimage; meanings; foucaultian archeology-genealogy; realities.

Cite como

\section{(ABNT NBR 6023:2018)}

CRUS, Judite Zamith. Um arquivo aberto de Ana Luísa Janeira: a transformação pela viagem. Dialogia, São Paulo, n. 39, p. 1-13, e20602, set./dez. 2021. Disponível em: https://doi.org/10.5585/39.2021.20602.

American Psychological Association (APA)

Crus, J. Z. (2021, set./dez.). Um arquivo aberto de Ana Luísa Janeira: a transformação pela viagem. Dialogia, São Paulo, 39 , p. 113, e20602. https://doi.org/10.5585/39.2021.20602. 


\section{Introdução}

Para reflexão, acedi a dois posts do blogue ArquivoVivido, numerados e intitulados, por JANEIRA (17 dez. 2020), na seguinte ordem: 5. Para uma epistemologia de viagem; e 2. Viajar, colecionar, arquivar - Coisas \& loisas de muitas paragens com saberes, sabores e odores.

Partindo da aventura no Extremo Oriente de Fernão Mendes Pinto (1510/15 - 1586), escritor em múltiplos géneros, foi publicada, em 1615, Peregrinação (PINTO, 2009). Da devoção e missão, desenrolam-se significados para viagem, que mudam com os tempos, espaços e discursos.

Ana Luísa Janeira o descobriu na infância, devolvendo-nos o trazido sabor e cheiro de paragens exóticas, à época de saberes esconsos, nas curas com especiarias para fins terapêuticos, levadas ao Século XVIII, quando instituições poderosas os contiveram, de farmácias a laboratórios europeus.

\section{Sobre o questionável de textos históricos}

A "primeira narrativa portuguesa de viagens" teve um cunho bem além de informativo e descritivo. O escritor primou pelo caráter estético da obra vivida. Conta-se que sobreviveu 21 anos fora de Portugal, em viagens de perseverança, 13 dos quais cativo e 17 vendido. No Brasil, o período colonial traria outra marcação do quinhentismo, de "informativo" (por viajantes e missionários) a "catequizante".

Poder-se-á hoje crer que sejamos conformados constitucionalmente à criação fácil de uma polaridade concetual (A ou B). Para dentro-fora de Portugal, como a autora o afirma, entre externo e interno conjugam-se duas óticas: in-ótica e ex-ótica. Depende de perspetivas sobrepostas de ver e de fixar o olhar no mais sofisticado discurso.

Na filosofia da pesquisadora conhecem-se visões do mundo e "configurações epistémicas", introduzidas por ver o mundo nas boticas, bibliotecas, gabinetes de curiosidades e museus. De espaços quotidianos e instituições sobressaem, fixados, tanto "os limites do permitido-proibido", quanto os saberes nem dominantes a "relembrar".

Num rasgo para o relato da perplexidade, afinal, a história narrada capta a história do pensamento, numa alusão a COLLINGWOOD (2005, p. 10). Como o evidenciou o filósofo idealista britânico, no que tange o significado de conceitos, visa-se tanto o conhecimento da "verdade" como episteme ("ciência" no grego).

Sobre a verdade?

A fantasmagoria mesclada de evidência de um Fernão Mendes Pinto dá ensejo a um popular jogo de palavras: "- Fernão Mentes? Minto." O português viveu sem suporte para dizer o que fosse 
significativo, na partilha multifacetada do mundo. A resposta apanhou-o em inverdade assumida: "minto...".

"Não mentir" aproximou-se, entretanto, da ideia da pessoa não se contradizer. Ensinamnos, em crianças e sobretudo pratica-se a coerência, quando seja pensado que possamos aprender a não nos auto contradizermos. Será que as pessoas ainda são assim coerentes?

A “teoria" do autor poderia ser fundamentalmente emocional, assente em crenças e povoada por sistemas dinâmicos interpessoais para a criação de significado. Estes nascerão das perceções das relações estabelecidas entre as partes e o todo (dum episódio para uma narrativa) e das relações entre fins (missão religiosa, riqueza...) e meios (viajar), a faceta extrínseca. A esse significado truncado alia-se ainda o lado intrínseco, portanto, captado na perceção subjetiva da relação e a partir do contexto inóspito.

\section{Um tempo de viajantes em busca de riqueza}

O alargamento do "Império, d'Aquém e d'Além-Mar" deu-se de Portugal, tanto para a Índia como com o achamento do Brasil, em 1500.

Mas foi no longo reinado de D. João I que a expansão marítima de Portugal teve início, em 1414, aquando da "tomada" de Ceuta, em África, local para as rotas de especiarias e de ouro. Comercializado por árabes, esses "sarracenos" logo deslocaram o traçado no mapa, sem prejuízo maior. A visada superação de entraves no comércio, rumo à Índia, terá sido de extremo custo, na viragem do Cabo Bojador, em 1434, ainda no atual Marrocos, e no Cabo da Boa Esperança (atual África do Sul), em 1488.

Pensado tal troço preciso, no tempo longínquo, um viajante pode ter vislumbrado um específico legado material e deixou-nos um saber imaterial, no livro Peregrinação. A vida de Fernão Mendes Pinto atravessaria ainda assim cinco reinados de Portugal, talvez menos reconhecidos do que a sua escrita de há 400 anos: na 2. ${ }^{a}$ Dinastia de Avis, com os reis portugueses D. Manuel I (1495 - 1521), D. João III (1521 - 1557), D. Sebastião (1557 - 1578) e o Cardeal D. Henrique $(1578$ - 1580) e, na 3. Dinastia, a Filipina, com Filipe I (1581 - 1598).

Seguiu-se esse período da história europeia, entrecortado pelo que já foi designado de sonambulismo intelectual, na ausência de questionamento. Terá sido em 1900 que um novo período axial nos abriu as fronteiras. Progressivamente, o cidadão comum submergia naquela perceção pessoal (fenomenologia), firmada na visão direta dum mar de rostos em transformação. Ao viajarem mudavam de território e, nessa viragem fenomenológica, o planeta tornava-se somente então menor. Era reconfigurado pelo conhecido de gentes, paisagens e diversidades. 


\section{Metodologia}

A identificação de um modelo é limitada pela experiência de etiquetagem que temos e pelas escolhas que façamos. Pelos métodos qualitativos explicita-se uma impossibilidade de objetividade e de neutralidade para quem é intérprete do mundo e formula construções ideológicas num texto.

É a linguagem simbólica que nos permite transcender a experiência direta, donde nem existir um instrumento melhor do que o sistema simbólico (sendo humano), no que distingue a Análise de Discurso (ÍÑIGUEZ-RUEDA, 2006): conduz a ver diferentemente. Com essa meta teoria efetuamos uma "operação" (de alguma forma), o que implica explicitar a investigação a quem a leia. Entender um texto é analisá-lo, ou seja, “desconstruir” um signo. Orienta-se essa mensagem ao processo relacional e cognitivo, em que teoria e metodologia acentuam a cultura. Não se visa a comunicação, como na técnica de análise de conteúdo, codificados sistemas de categorias. Destacase a hermenêtica dupla (GIDDENS, 1985), enquanto sejamos "utilizadores-de-conceitos" competentes e agentes "confinados" ao conhecimento impreciso e parcial de realidades "cooperativas". Diversamente, nas ciências da natureza, cuja posição da natureza é "adversária" (não se deixando conhecer), demonstra-se como o mundo natural esteja estruturado, com base em “definições operacionais" para a "prova da realidade".

E se a linguagem representa a linguagem, a "realidade" é antes constituída pelos nossos valores, sentimentos, crenças, desejos, expectativas sobre uma obra. Afinal, a realidade é a atividade mental. Acresce conferir o alcance do subtexto nos sentidos segundos, dito que neles nos aproximemos e afastemos na leitura aberta à arqueologia-genealogia foucaultiana, em que o discurso sobre o discurso (metadiscurso) conforma uma "arqueologia" no método sistémico. É voltado ao todo espacial situado e é contratualizada uma natureza histórica.

\section{De uma história adaptada para a infância}

Quase no final da análise textual de dois trechos, deparei-me no blogue suprarreferido com o que se entronca no nome daquela histórica figura de pícaro de Portugal, um dúbio exemplar na conceção duma narrativa indecidível e peregrina.

No ArquivoVivido, a filósofa conta como terá lido, em casa, o relato obtuso daquele, um exemplo positivo:

"Desenvolvi a minha natureza de viajante junto de Fernão Mendes Pinto, cabendo a meu Pai alimentar, desde sempre, a tendência: quando li a Peregrinaşão adaptada a crianças, senti entusiasmo e fiquei fascinada com tanta descoberta e aventura, lados a que mais me prendo" (JANEIRA, 17 dez. 2020). 
Pense-se que, quando o significado e o significante são uma conexão arbitrária, torna-se irrelevante chamar Peregrinação ou Viagem a um objeto. São nomes para um livro, no dito de um discurso que remete para o que seja meramente convencional.

Poder-se-á afirmar então que "Para cada um dos seus nomes, a linguagem deve conter um nome para o sentido deste nome” (DELEUZE, 1998, p. 32)? Definitivamente, o inconsciente?

Essa é ainda uma forma analógica de conferir ao significado "óbvio" o que, ainda seja dependente da linguagem em contexto e contratualizado no dito, ajustado e nem sempre correto.

O contratualismo é muito menos conhecido do que o contextualismo e do que o intrapsiquismo. O termo verbal "contratar", na raiz latina (v. tractare), pontua o gerir algo ou envolverse numa ação, mas também pontua o "contrair" ou o "concordar". Na atualidade, mediante "contratos" firmados, somos participantes ativos nos processos dinâmicos de experienciar situações e de modificar o significado intersubjetivo. Nesse sentido de agencialidade, uma plateia no teatro pode ser envolvida em contrato tácito e "participar" na representação. No ensinoaprendizagem, os nossos processos (predominantemente tácitos) de "contratação" far-nos-ão mudar os significados.

\section{Espaços precisos para a leitura concisa do mundo}

A dependência do cenário torna o significado nem universal, nem independente da situação e do conhecedor.

Ana Luísa Janeira assumiu uma perspetiva de descontinuidade histórica, tanto alusiva ao conhecimento epocal paradigmático (por exemplo, modelado pelo século XVIII europeu), quando seja "coexistente" com a visão de "espaços precisos". Os cenários preparam-se com ornamentos nos mais antigos "laboratórios", as boticas.

Mas antes dessa ilação, justifica-se uma margem de reconhecimento, que cabe à história da História: que saber, no aprendido, de novo e viável, criativo.

Sem dúvida, uma divulgação sobre os usos dados a especiarias coube ao estranho participante, que recriou situações humanas invulgares, nem sempre favoráveis ao famoso espírito de "cruzada", aprontados valores de desonra e desculpa (que nem seja engano).

$\mathrm{Na}$ sequência do fundamento ficcional, foi no 2. ${ }^{\circ}$ ano de estudos, no Liceu Rainha Santa Isabel, no Porto, que Ana Luísa Janeira (nome original) foi denominada Fernão Mendes Pinto, por Ana Paula Quintela Ferreira, uma colega de turma, autodesignada de Alcipe. Em meados do século passado teriam cerca de 12 anos.

Mas Alcipe? 
Uma mulher torna-se mais difícil de buscar na história, colocada na outra margem, para mais poeta. Pois, foi a custo que descobri o nome pelo qual ficou conhecida Leonor de Almeida Portugal de Lorena e Lencastre, que viveu entre 1750 e 1839, ainda que filha do Marquês D. João de Almeida Portugal, destacado na corte do segundo e último monarca, Rei D. Pedro II do Brasil (1825 - 1891), durante a 4. ${ }^{a}$ Dinastia de Bragança.

O motivo imediato para os nomes atribuídos prender-se-ia com a circunstância de Ana Luísa Janeira "mandar as notícias do Oriente” (JANEIRA, 2010, p. 16), enquanto Ana Paula "mandar as cartas de prisão" (p. 16). Os pseudónimos, que nem eram nicknames, partiram da prévia troca de correspondência de férias, vindo a implicar uma nova nota de viagem enviada do levante, por Ana Luísa Janeira à antiga colega, quarenta anos mais tarde.

Os nomes não verdadeiros de ambas seriam divulgados em privado. Poderia preservar-se o gosto pelo secretismo, comum numa transição de pré-adolescência "inquieta". O verdadeiro "eu" nem existe, nem é real?

O “eu” é aparência, vulnerável e sujeito a influências.

Acresce que, por condição epocal, via-se a ditadura espelhada na censura prévia, antes mesmo de 1933, quando António Salazar tomou o poder autocrático de 41 anos ininterruptos, terminado em 1974.

Ao afastamento no imaginário de casa, no Porto, poderia contrapor-se a "prisão" de nela viver Alcipe.

Portanto, o relato de um acontecimento constituído em feito, com efeitos vitais, é composto de uma estrutura (DELEUZE, 1998), dito que esta albergue o incógnito, uma situação específica, esgueirada numa história com rostos viventes, havendo por vezes escapatórias aos cânones da narração.

\section{Sentido de viajar para o empreendimento, na prática de novas ideias}

O que se volta a detetar num Fernão Mendes Pinto?

O vivido subjetivo, no sentimento sentido para o conceito de "viagem", retomados no blogue (JANEIRA, 17 dez. 2020): 5. Para uma epistemologia de viagem. Desvela-se a figura do inédito, quando a filósofa enfatiza numa breve nota: "Porque o encontro com o desconhecido alimenta o imaginário, nunca teremos a certeza sobre as peripécias efectivas da Peregrinação, de Fernão Mendes Pinto.". Viajar alcançou finalidades de poder-saber, depois das suas expedições, tanto em (auto)conhecimento como do acessível meio (inter)subjetivo extravagante. 
Outras peripécias e designações envolvem "viajar” (JANEIRA, 17 dez. 2020): se "o século XVIII imaginou uma viagem especial", dita "filosófica", em Portugal, seguiu-se a viagem por "missão (com origem na diplomacia, na religião)", além de fronteiras estritas, a "expedição (com origem militar)", a "comissão" (uma (co)missão com origem administrativa), enquanto chegamos aos "projetos (com origem legislativa, em arquitectura e engenharia" do século XX, sem esquecer os "programas (cuja origem seja política e educativa) (JANEIRA, 17 dez. 2020).

E depreende-se que os fenómenos, nas abordagens às ciências humanas e sociais (i.e., ações psicossociais de vários tipos), surjam constituídos como quadros de referência e interesses, dando conta da fluidez das palavras para sentidos segundos, numa base para as análises textuais.

No reportado a Ana Luísa Janeira, uma Filósofa das Ciências, nem esta será somente uma observadora distanciada, porque busque perspetivar coisas e ideias, do nível concreto a abstrato. Passa do que veja fazer-se (o processo de trabalho prático ou teórico, filosófico e científico) ao que esteja elaborado (o produto de conhecimentos ou saberes), sem esquecer o que poderia ser feito, envolvida em meios in-óticos (versões do mundo a partir "de dentro") e espaços ex-óticos, sublinhado o exotismo de outras paragens. Para tanto, quando transportada num outro lado do mundo, a pesquisadora possui uma visão panorâmica do real e do virtual, conhecido o ocorrido num dado espaço-tempo invariavelmente diferente e incorporado. A vida real da autora agarra o lugar, no "real da topia" e nem nos confronta com utopias de ilhas perfeitas lá longe. Decorrentes das suas práticas de vida, os conceitos elusivos ajudam-nos a bifurcar e a demarcar o que as nossas ações "sejam", o que "signifiquem", nem somente numa via direta, literal ou explícita. Essa versão pode ser fechada a um paradoxo holístico. No paradoxo firmam-se palavras e frases, que antecedem o texto na totalidade. Que dizer de conhecer-se somente o texto pela compreensão de partes coligidas?

Nessa versão do mundo polimorfo, tornam-se inseparáveis o conhecimento (ativo, corporificado e com suporte emocional), o ato de conhecer, viajando, e o próprio conhecedor. A filósofa criará nexos com Menon, trazido ao paradoxo, ao contrassenso, o que foi desconectado da história Portuguesa instituída. Na falta de liberdade de expressão, utilizámos já conceitos a medo, esquecendo histórias-caso no Português, no interdito e na lei imposta, ou seja, uma dupla condição de já visto (DELEUZE, 2005). Outras categorias de reparo são o "inédito" do discurso da investigadora, tão "impertinente" quanto criativo, vivendo nós tantas vezes no "indecidível”. 


\subsection{Sentidos de coisas \&o loisas: património material e legado espiritual}

No blogue ArquivoVivido, em 2. Viajar, colecionar, arquivar - Coisas \& loisas de muitas paragens com saberes, sabores e odores, JANEIRA (17 dez. 2020) foca tempos_anteriores (medievais) e posteriores (modernos) ao momento captado pelo criador de Peregrinação, uma obra póstuma.

A par do auge da expansão marítima portuguesa, cerca de 1500, Portugal já contava com outros registos "informativos", sobre umas quantas experiências de cruzada, num hiato dado ao enriquecimento, que enfatiza a transformação pela palavra da "realidade" (coisa, bem material, pessoa venal, sociedade feudal, cultura espartilhada...).

Trazer de volta a palavra "verdade" voltará ao reconhecido do "conhecimento moderno verdadeiro", entre um "património material e um legado espiritual", dois séculos depois da vida de Fernão Mendes Pinto, em pleno século das luzes ou da razão.

Afinal, o próprio autor viveria às portas por abrir de um 2. ${ }^{\circ}$ período axial $(1600$ - 1750), marcado pelo advento da crítica que sobreviveria no espírito da revolução científica.

\subsubsection{O legado da botica?}

Na Península Ibérica, a bodega foi datada, em 1326. Mas já fora escondida desde o século $\mathrm{X}$, senão antes, a arte da “cura”. E da botica ou apoteca (no latim, “adega” ou "armazém”) separouse a "científica" farmácia, alcançado o símbolo da cobra (poder) e o do recetáculo curador, no século XVIII. A palavra transformaria a posse da coisa (res- no latim e rei-, nas línguas indoeuropeias significando "propriedade"), a realidade adquirida como arte liberal e ciência. "A botica é o espaço onde é praticada a ciência\&arte do medicamento, produto para curar uma qualquer perturbação na saúde, desarmonia de humores, como queriam os hipocráticos” (JANEIRA, 17 dez. 2020). Numa e noutra botica descobriam-se e encobriam-se saberes. Eram resgatados saberes nem iluminados no século XVIII.

A par de livros de mezinhas para curar, havia obras proibidas, por regimes políticos, entre outros. Os outros livros, "malditos", foram classificados, no "Índex de livros proibidos". No latim, Índex Librorum Probibitorum, listou-se um rol metódico de escritas, em que a Igreja Católica recusou a difusão de livros, por entendê-los como heréticos, eróticos ou contrários aos dogmas, entre 1559 e 1948. Com a abolição definitiva em 1966, obras literárias e entraram e saíram do Índex, podendolhe retornar, por quatro séculos.

Muitos manuscritos foram abafados como um saber prático desvalorizado, "enganoso" ou engagé, inacessível a leigos, desconhecedores da língua arcaica ou estrangeira. Poderiam ser parcialmente integrados numa parede ou pilar arquitetónico, ou tragados ou restaurados na "botica, 
parente da bodega e do botequim, pelos 'espíritos” em que banham as suas águas”. Nas "águas” das adegas (de vinhos) contam-se monstruosidades escutadas, servidas cheirosas bebidas alcoólicas, tal como a apoteca enfeitice com o elixir cor de açafrão.

Por espírito de pesquisa, pensemos ainda no contributo impressionante, dado pelos conventos à arte farmacêutica, colocado no texto e em marcha todo um motor para a noção de "saber-fazer" na botica: o que faça bem ao corpo e à mente.

Seria essa praxis (convergindo para um fim) contrastante e descontinuada de um "saberpoder" (sem convergência política e social), nomeadamente pelo domínio académico de livros herméticos. Na botica, cumpria-se o préstimo de "saber-curar", por se "saber-fazer". Logo, nela havia "mesclas, misturas, miscelâneas", por contraste ao saber de universidades (afastadas de artes e ofícios medievais), primando pelo moderno, pelo modelo analítico-sintético, na perspetiva da autora, para o impacto do "método científico". O formato de produção permeou um sistema de relações com efeitos, na isenção de censura da Academia Real das Ciências de Lisboa, no Convento de Jesus da Ordem Terceira de S. Francisco e, entre outros serviços, nos laboratórios de química.

No final do documento, o auscultado remete à questão pesquisada: “Gabinetes, Boticas e Bibliotecas, o que têm em comum?"

A resposta retoma a proposta de “o escondido" (por tácito, ambíguo, implícito) para muitos de nós, praticado por uns poucos, ou seja, um saber epistémico que viria a transformar-se inevitavelmente com o estudo académico reinante em gabinetes inacessíveis, trazidos de boticas esconsas e bibliotecas caseiras, depois do século XVIII.

\section{Do legado textual}

Peregrinação integrara surpresa, tensão face a possibilidades emocionantes, mistérios assombrosos, revelações e clarificações divinas fascinantes do "discernimento vocacional" do conhecedor.

Os textos de Ana Luísa Janeira possibilitam-nos manejar conceitos, separando-os e unindoos de formas novas, quando nos tragam os paradoxos do todo e das partes, da aparência e da realidade, as noções de permanência e mudança ou de unidade e diversidade.

O que recordar de Fernão Mendes Pinto?

Permitiu-se mostrar o lado artificial nas relações humanas, quando foi preciso uma dúzia de anos para o publicado roteiro de peregrino para um lugar sagrado, algo ofensivo do credível e imaginado. 
A pensadora esclareceu o valor de um património material e de um legado espiritual, ambos poderes de uns poucos. O português, iniciado de jesuíta, tornou-se um fura-vidas (por dinheiro?) e deixou-nos o legado espiritual.

Em termos materiais, ao longo do tempo, europeus guardaram (e continuam a possuir) "raridades", tesouros incalculáveis trazidos de fora. Vieram a figurar outros grandes poderes económicos, entre um grupo religioso e outro reinante. Desde tempos imemoriais, "papas, reis e príncipes" possuíram tesouros escondidos. Poucos fariam saber e aqueles fizeram poder.

Em paralelo, em termos espaciais, viajar permitiu a "coexistência e na sucessão, aproximam o mundo exterior e o mundo interior" (JANEIRA, 17 dez. 2020), além da coexistência do mundo material e espiritual.

Pois, em termos imateriais, conjuga-se assim uma "coexistência" entre o ato de atualizar um lugar (presentificado) e a estruturação (espacializada) deste. Como JANEIRA (17 dez. 2020) o enuncia, "o acto de conhecer, como o seu produto, o conhecimento, requerem uma certa atitude por parte do sujeito, ao mesmo tempo que mobilizam a necessidade de determinados espaços". A pensadora mobilizou-se para ir longe no pensamento duma história-caso sem paralelo.

Se esperássemos que nos contasse o segredo da sua ideia sobre uma criatura misteriosa, estávamos enganados. Pelo menos, era isso que eu esperava que ela esperasse.

$\mathrm{E}$ até independentemente dos nomes dados pelo pai e pela mãe, tal como o esclarecido de antemão, a "alcunha" nem é um nome verdadeiro de alguém.

Em Fernão Mendes Pinto? Muitas coisas estariam certas e muitas coisas estariam erradas, mas algumas coisas não parecem estar nem uma coisa nem outra.

Sobressai ainda a conjetura de a autora ver em algo um problema, nem porque se saibam as respostas todas. De valor é estar-se interessada nas perguntas, sobre as coisas que são reais, mas cujas relações estão apenas na nossa cabeça. Donde, o sentido das coisas (... ideias, pessoas) conduzir à descoberta ("lá fora”) e - diz-se - inventado (“aqui dentro”), logo, construído.

\section{Mundos virtuais: “A que lugar queres ir, agora?”}

"Quero ir a uma busca do tesouro com internautas!"

"Vivemos" já em "espaços" seguros e protegidos (numa sandbox), onde podemos até fazer o que queiramos, adquirindo o poder de transmutação.

Quando sejam os "mundos" focados, com elfos ou trolls, passaram ao caráter lúdico, sem esquecer os jogos de papéis multiutilizadores (em inglês, MMORPG - massively multiplayer online role playing games). De outros universos vêm aqueles com quem se contracene, vindo dos romances de 
fantasy ou da ciência-ficção e o enredo pode ser vencer o invasor, recuperar-se um património material em preciosidades.

$\mathrm{Na}$ atualidade, alcançámos então já o direito de pertença a vários mundos e adotamos dia a dia identidades de ficção, nem sempre sem prejuízo: «quem sou eu?».

Estaremos a recriar num contexto de formas enviesadas personalidades múltiplas ou avatares... E chegamos a encontrar parceiros astronautas ou cavaleiros em busca do tesouro roubado e perdido no galeão. E feito um perfil, na busca de novos amigos fazem-se mudanças de pormenor para impressionar, da figura, à idade e ao sexo.

A minha irmã mais nova já foi ensinada a saber como ensaiar deslocamentos, sem sair de casa, noutro mundo. E ensinou-me o que fazer, sem custo: "apanha-se" uma figura encarnada (personagem 3D), no jogo de vídeo World of WarCraft. Depois, essa "pessoa" vai quase para onde queira, explorar o meio, com vários jogadores em linha. "Muda-se o mundo".

Chega-se ao mundo sem narração, como Second Life, visado o encontro de trabalho, numa atividade económica (com o liden dolar).

$\mathrm{Na}$ Yahoo ou na IBM recrutam-se pessoas que aprenderam jogos (de estratégia), porque alcançaram competências superiores no foco/atenção, cooperação, organização das coisas e estruturação espacial, inclusive a competência de liderança giratória e de gestão.

Quando muda a forma e a conduta por prazer e interesse em mundos virtuais?

Infere-se alterada a perceção da realidade e a própria imagem, que nem agrade por evitante ou furtiva. Designou-se de "efeito Prometeu" à transformação operada na pessoa, até mesmo monstruosa, partindo do deus mitológico, que daria conta do destino revelado. Outra condição nefasta é o alter ego virtual poder conduzir a um avatar do duplo, ou seja, a pessoa vai fazer algo, por comando do avatar (desejado parecido consigo) numa realização ou atividade custosa como realizar exercício físico.

\section{Discussão final}

$\mathrm{Na}$ situação de uma criança refugiada ou imigrante, aprendida a língua, sobrevive melhor ao estranho. Algures esbarra-se com o mundo e a alteridade, o outro diferente de mim. Entre nós, não estará adormecida uma figura de pasmo. Num fermento de regeneração, nem todos os filmes, jogos de computador ou livros irão germinar algo como uma lição de vida. Mas quando visamos um espaço a partir de fora entendido, um mundo ampliado e, depois, lá fora, para além daqui, onde iremos? 
Nem todos os textos nos mudam e caem-nos das mãos, quando nem sejam para nós, num dado momento de vida.

O poder das imagens diretas em ecrã constituirá uma via, por vezes barrada à metalinguagem e ao significado reflexivo, acedidos pelo caminho longo cerebral.

MARIELLE MACÉ (2011) fez questão de colocar "modos de ser" em situação de relação com "modos de ler", dito que nem sejam categorias de opostos (ser e ler). Nem escapa o estereótipo de género ("ele lê livros de guerra, ela lê livros de amor"), nem o travão ao medo de uma guerra e de um amor ensaiado.

A leitura chegará a imiscuir-se e a germinar no terreno do "eu” mais perene e volátil do que a experiência efetiva. Quem diz experiência poderá acrescentar o valor conferido ao sonho de lá ir, quanto de encontrar a relação entre emoção forte e significado atada àquele mundo de imaginação. Que aventuras viveu em emoção aquela ou esta personagem?

A ficção alcança uma justificação por função vital, para o filósofo da linguagem, porque as neurociências chegaram à evidência de que os estados mentais do protagonista sejam levados e induzidos no leitor, sem os viver (SCHAEFFER, 1999).

Pela leitura virão tanto a aquisição de ritmos de viver, quanto os modos de existir agarrados à prisão de Alcipe ou à pequena ilha, o que MACÉ (2011) identifica como puissances de façonnement, ou seja, toda uma multiplicidade de "modelagem de poderes" para fazermos as coisas, em realizações e/ou performances.

A pessoa que leia alcança ainda uma diferença destacada pelo sair de si mesma, agente do seu destino, escolha. Mas a leitura não fornece "receitas" de como viver melhor. Num dia de 2002, Jacques Derrida contou, em Braga, durante um encontro numa feira do livro, o inesquecível na assistência. Quando um jovem de 17 anos o inquiriu sobre os ganhos em ler, Derrida ter-lhe-á respondido que, se num dado momento crítico, uma pessoa em quem confiasse lhe oferecesse o livro certeiro à questão por responder, aí teria o argumento para ler. Sem "sermões", ganharia voz. Não pensava pelos discursos de outros. Emancipava-se do saber dos que o cercam, ultrapassado o espaço doméstico e as regras impostas.

As aventuras e descobertas de Fernão Mendes Pinto conjugam essa metalinguagem na variação sem paz de imaginação e de um poder ser, quando abalroasse limitações, possibilidades e desejos por cumprir. 


\section{Referências}

COLLINGWOOD, R. G. The idea of history with lectures 1926-1928. In: DUSSEN, J. (Ed.), with na Introduction (Revised Ed.). Oxford: Oxford University Press, 2005.

DELEUZE, G. Conversaçoes. Trad. Peter Pál Pelbart. São Paulo: Editora 34, 1998.

FOUCAULT, M. Arqueologia do saber. Trad. Luiz Felipe Baeta Neves. Rio de Janeiro: Editora Forense Universitária, 1986.

GIDDENS, A. The constitution of society: Outline of a theory os structuration. Berkeley/Los Angeles: University of California Press, 1984.

ÍÑIGUEZ-RUEDA, L. Análisis del discurso. Manual para las ciencias sociales 2a . ed. Barcelona: UOC, 2006.

JANEIRA, A. Figuras e configurações do Porto: Marcas em espaços escolares. Lisboa, Portugal: Apenas Livros, 2010.

JANEIRA, Ana. 5. Para uma epistemologia de viagem. Blog Arquivovivido. Lisboa, 17 dez. 2020. Disponível em: https://arquivovivido.wordpress.com/os-meus-espacos-de-construcaoproducao-intelectual-cultural/viagens/. Acesso em: 20 jun. 2021.

JANEIRA, Ana. 2. Viajar, colecionar, arquivar - Coisas \& loisas de muitas paragens com saberes, sabores e odores. Blog Arquivovivido. Lisboa, 17 dez. 2020. Disponível em:

https://arquivovivido.wordpress.com/os-meus-espacos-de-construcao-producao-intelectualcultural/viagens/. Acesso em: 20 jun. 2021.

MACÉ, M. Façons de lire, manières d'être. Paris: Callimard, 2011.

PINTO, F. M. Peregrinação. Lisboa: Companhia das Ideias, 2009.

SCHAEFFER, J.-M. Porquoi la fiction? Paris: Seuil, 1999. 